\title{
A rare entity of acute renal failure: retained foley
}

\begin{abstract}
Retained foreign bodies in the urinary bladder are not uncommon. They can present in the form of irritative or obstructive symptoms. In literature, a variety of retained foreign bodies have been described. Methods of introduction can be an iatrogenic, accidental, postoperative complication, or migration from perivesicular vicinity. We described a severe presentation of a case where a retained foley ended up in the formation of large calculous formation. Our patient presented with acute renal failure resulting in irreversible kidney injury. Open cystostomy was done to remove the stone and retained foley and the patient was discharged with permanent dialysis arrangement.
\end{abstract}

Keywords: urinary bladder, renal failure, prostate, foley catheter, antibiotics

\section{Case Description}

A 57-year-old male with a past medical history of Benign Prostate Hypertrophy (BPH) was admitted with altered mental status. Due to patient altered mental status history was obtained from family members. The patient used to live alone and was able to take care of his activities of daily living. He was found confused and covered in feces and urine by his family members. The last well known was 1 week ago. The patient was seen in hospital 5 years ago for urinary retention. A temporary Foley catheter was placed at that time and the patient was counseled to follow outpatient with the urology. However, patient never followed outpatient with urology. Physical exam revealed cut Foley at the external urethral meatus. Upon admission, lab findings were significant for severe uremia and acute renal failure with Bun of $192 \mathrm{mg} / \mathrm{dl}$, Creatinine $17.7 \mathrm{mg} / \mathrm{dl}$, and Potassium $7.3 \mathrm{mmol} / \mathrm{L}$. Other significantly abnormal labs included $\mathrm{Hgb} 5.7 \mathrm{~g} / \mathrm{dl}$, Wbc $17.2 \mathrm{k} / \mathrm{mm}^{3}$, Platelet $450 \mathrm{k} / \mathrm{mm}^{3}$, Bicarb $9 \mathrm{mg} /$ dl. CT abdomen and pelvis without contrast showed $5.6 \times 6.0 \times 4.4 \mathrm{~cm}$ calcified stone with retained Foley in the urinary bladder FIGURE 1. There was severe bilateral hydronephrosis and hydroureter. Both kidneys demonstrated cortical thinning suggesting chronic renal disease. All these findings were suggestive of chronic urinary retention caused by BPH and by the formation of stone around the retained foley. Urinalysis revealed cloudy urine, presence of leukocyte esterase, hematuria, pyuria, and bacteriuria. CT scan of the head without contrast did not reveal any acute intracranial abnormality.

The patient was admitted to ICU, intubated for airway protection and was started on broadspectrum antibiotics e.g. cefepime. 3 units of blood were transfused. Emergent dialysis was done after temporary indwelling dialysis catheter placement, consecutively for 3 days. Blood cultures were sent which later grew Citrobacter koseri and Proteus mirabilis; both sensitive to cefepime and ceftriaxone.

He underwent open cystostomy with the removal of bladder stone and retained Foley en-bloc with suprapubic catheter placement FIGURE 2.

The patient had a retained Foley that later underwent calcification and a large bladder stone formation. He was able to urinate from half cut retained part of Foley which was placed 5 years ago. Once the Foley catheter lumen was occluded, he was unable to urinate and subsequently developed renal failure. During this hospitalization, telepsychology consult was placed regarding the patient's inability to make a decision for himself and lack of insight regarding

\section{Asma Jamil ${ }^{*}$, Rajesh Gulati ${ }^{1}$ and Ayesha Jamil ${ }^{2}$}

${ }^{1}$ Department of Internal Medicine, Riverside Community Hospital, USA

${ }^{2}$ Department of Internal Medicine, St. Mary Hospital, USA

*Author for correspondence: Jamilasma40@gmail.com 

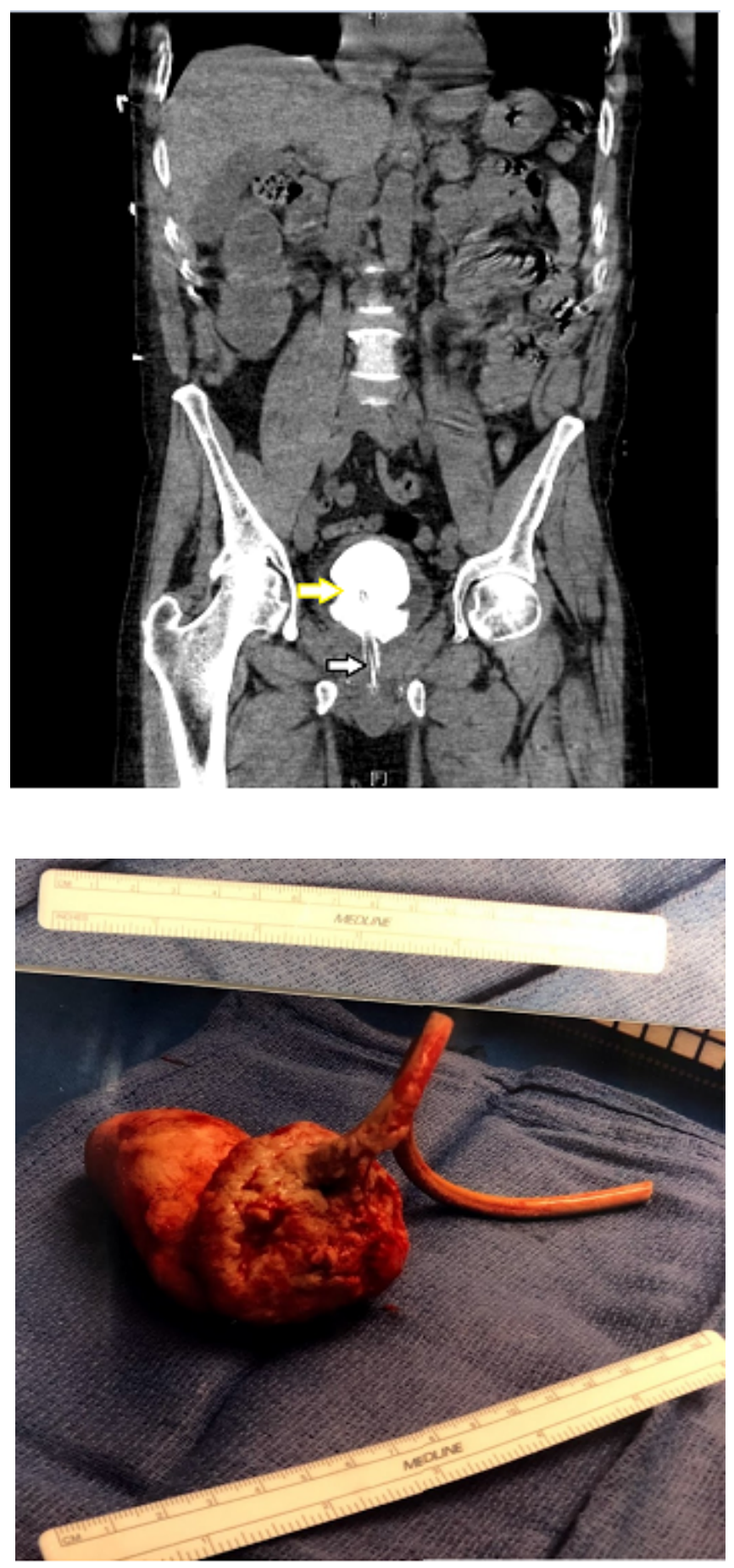

FIGURE 1. The yellow arrow represents bladder stone formed around the retained Foley. The white arrow represents part of the retained Foley in the penile urethra.
FIGURE 2. Large bladder stone with partially cut retained Foley. his disease. He was diagnosed with cognitive impairment secondary to chronic kidney disease or from brain's microvascular disease.

This patient developed serious postobstructive renal failure and remained on dialysis even after emergent treatment. Suprapubic Foley was removed and he continued with Foley to drainage. AV fistula was constructed as a dialysis access route. The patient was later discharged to a rehabilitation center and a dialysis chair was been arranged three days a week before discharge.

\section{Discussion}

Retained foreign body in urinary bladder described in the literature includes Foleys catheter, burst pieces of Foley balloon, pencils, batteries, electric/cable wires, hair clips, kidney beans, fork, glass ampoule, IUCD, leech, pieces of gauze, and pieces of gloves [1,2]. The most common etiologies include psychosocial 
disorders, iatrogenic causes such as selfcatheterization, and post-op complications, sexual practice under intoxication and autoerotic purposes [3].

Long term Foley retention can lead to bladder fistula formation, stone formation, or it can remain asymptomatic. In a case study, a retained Foley was recovered after 20 years endoscopically without complications [4].

$60 \%$ of foreign bodies are entered via the transurethral route and $30 \%$ via the transbladder route [5].

Any object surrounds the bladder can migrate into the bladder. Migration of sutures has been described in literature used for bladder neck suspension, where sutures as a foreign body were migrated despite being sutured applied [6]

Retained lower urinary tract foreign bodies can present both as obstructive symptoms i.e. suprapubic or abdominal pain, hematuria, urinary retention, and irritative symptoms i.e. dysuria, frequency, urgency and urinary incontinence [7]. In severe cases, bladder perforation has been reported [8].

Lower urinary tract foreign bodies are usually diagnosed on plain films (KUB), ultrasound, CT scan, and cystourethrography. In some cases advance techniques e.g. cystoscopy is used for diagnosis [9].

Encrustations around chronic indwelling Foley can lead to difficult removal and it can get stuck requiring surgical intervention. Retained Foley and its parts act as a nidus for stone formation. Urease forming bacteria e.g. Proteus form a biofilm around the Foley which leads to stone formation [10].

Treatment is based on location, nature, size of foreign body and age of the patient [7]. Cystosurethrostomy mediated removal is usually attempted, however if the endoscopic approach fails, or objects are calcified, open surgical approach is used such as suprapubic cystostomy (posterior urethral or large intravascular foreign bodies). ESWL has also been used for retained foreign bodies resulting in stone formation [11].

\section{- Teaching points}

1. Be mindful of Foley catheter complications and its implications

2. History regarding urologic interventions in the past helps identify the cause of a patient's clinical presentation

\section{Conclusion}

Our case is a rare presentation, where a retained Foley in urinary bladder underwent calcification and stone formation. This case ended up with some severe consequences in the form of permanent renal failure and dialysis dependency.

\section{Source of Funding}

None

\section{Equal Author Contribution}

Statement

All authors have equal contribution to the preparation of this article. 


\section{REFERENCES}

Jain A, Gupta M, Sadasukhi TC, et al. Foreign body (kidney beans) in urinary bladder: An unusual case report. Ann Med Surg (Lond). 32, 22-25 (2018).

Datta M, Ghosh M, Biswas S. Brief communication foreign bodies in urinary bladders. Saudi J Kidney Dis Transpl. 22, 302-305 (2011).

Temiz MZ, Dincer M, Kandirali E. Bladder stone secondary to retained foley catheter balloon in a woman. I Acad Res Med. 5, 131-133 (2015).

Sarpal R, Agarwal S, Pathak P, et al.
Retained foreign body in urinary bladder: A case report. Imp J Interdiscip Res. 2, 11 (2016).

Shimokihara K, Kawahara T, Hayashi Y, et al. Foreign body in the bladder: A case report. Int J Surg Case Rep. 32, 22-24 (2017).

Cardozo L. Recurrent intra-vesical foreign bodies. Br J Urol. 80, 687-687 (1997).

Odoemene CA, Onuh CA. Foreign bodies in the urinary bladder-Case series. $J$ West African Coll Surg. 7, 124-136 (2017).

Bansal A, Yadav P, Kumar M, et al.
Foreign bodies in the urinary bladder and their management: A single-center experience from North India. Int Neurourol J. 20, 260-269 (2016).

Mibang N, Faridi MS, Rahman MJ, et al. Glass ampoule in urinary bladder as a foreign body. Asian J Urol. 3, 96-98 (2016).

Christopher CK Ho, Khandasamy Y, Singam P, et al. Encrusted and incarcerated urinary bladder catheter: What are the options? Libyan J Med. 5, 1 (2010).

Naidu K, Chung A, Mulcahy M. An unusual urethral foreign body. Int J Surg Case Rep. 4, 1052-1054 (2013). 